\title{
Mitochondrial Disease and Endocrine Dysfunction
}

Jasmine Chow ${ }^{1}$, Joyeeta Rahman ${ }^{2}$, John C Achermann ${ }^{2}$, Mehul Dattani ${ }^{2,3}$, Shamima Rahman ${ }^{2,4, *}$ ${ }^{1}$ Department of Paediatrics, Queen Elizabeth Hospital, Hong Kong

${ }^{2}$ Genetics and Genomic Medicine, UCL Institute of Child Health, London WC1N 1EH, UK

${ }^{3}$ Endocrinology Unit, Great Ormond Street Hospital, London WC1N 3JH, UK

${ }^{4}$ Metabolic Unit, Great Ormond Street Hospital, London WC1N 3JH, UK

* Author for correspondence

Address for correspondence:

Mitochondrial Research Group

Genetics and Genomic Medicine

UCL Institute of Child Health

30 Guilford Street

London WC1N 1EH

UK

Tel: +44(0)207 905 2608, Fax: +44(0)207 4046191

Email: shamima.rahman@ucl.ac.uk 


\begin{abstract}
:
Mitochondria are critical organelles for endocrine health, housing steroid hormone biosynthesis and providing energy in the form of ATP for hormone production and trafficking. Mitochondrial diseases are multisystem disorders of oxidative phosphorylation that are characterised by enormous clinical, biochemical and genetic heterogeneity. Currently mitochondrial disease has been linked to greater than 200 monogenic defects encoded on two genomes, the nuclear genome and the ancient circular mitochondrial genome located within the mitochondria themselves. Endocrine dysfunction is often observed in genetic mitochondrial disease and reflects decreased intracellular production or extracellular secretion of hormones. Diabetes mellitus is the most frequently described endocrine disturbance in patients with inherited mitochondrial disease, but other endocrine manifestations in these patients may include growth hormone deficiency, hypogonadism, adrenal dysfunction, hypoparathyroidism and thyroid disease. Whilst mitochondrial endocrine dysfunction is frequently in the context of multisystem disease, some mitochondrial disorders are characterised by isolated endocrine involvement, and it is anticipated that further monogenic mitochondrial endocrine diseases will be revealed by genome-wide next generation sequencing approaches. Understanding the mitochondrial basis of endocrine disturbance is key to developing innovative therapies.
\end{abstract}




\section{Introduction:}

Mitochondrial diseases are a clinically heterogeneous group of disorders that directly or indirectly affect the function of the mitochondrial respiratory chain and oxidative phosphorylation (OXPHOS) system (Figure 1) [1]. They are estimated to affect approximately 1 in 5000 of the population and collectively can be regarded as the most common group of inborn errors of metabolism [2].

Inherited mitochondrial diseases are caused either by mitochondrial DNA (mtDNA) defects, or by defects in the nuclear genes encoding mitochondrial proteins [3]. These defects can affect the subunits of OXPHOS complexes, mtDNA translation and maintenance, mitochondrial assembly proteins and mitochondrial membrane composition.

This review focusses on endocrine dysfunction in primary genetic mitochondrial diseases, including the clinical features, genetic causes and underlying disease mechanisms.

\section{Systematic review strategy:}

In this article, a review of the current mitochondrial literature was conducted using Medline ${ }^{\circledR}$ database searches between August 2015 and January 2016 to retrieve articles related to mitochondrial diseases and endocrine dysfunction.

\section{Mitochondrial function:}

Mitochondria are dynamic cellular organelles with multitudinous functions, notably production of adenosine triphosphate (ATP), the unit of cellular energy, via OXPHOS. Nicotinamide adenine dinucleotide (NADH) and flavin adenine dinucleotide $\left(\mathrm{FADH} \mathrm{H}_{2}\right)$, produced mainly in the Krebs cycle and from fatty acid oxidation (both of these biochemical pathways are located within the mitochondrion), provide substrates to fuel the respiratory chain complexes embedded in the inner mitochondrial membrane. Electrons from hydrogen are passed from complexes I and II to complex III via the mobile electron carrier coenzyme $Q_{10}$, and from complex III to cytochrome $c$, another mobile electron carrier, and thence to complex IV, the terminal enzyme of the respiratory chain (Figure 1). Complexes I, III and IV act as proton pumps to generate an electrochemical gradient across the inner mitochondrial membrane. Finally complex $V$ (ATP synthase), powered by the electrochemical gradient, produces ATP from adenosine diphosphate (ADP) and inorganic phosphate [4]. Other mitochondrial functions include calcium homeostasis, production of reactive oxygen species (ROS) which are essential cellular signalling molecules, regulation of apoptosis, and the biosynthesis of all steroid hormones (glucocorticoids, mineralocorticoids, oestrogens, progesterone, androgens and calciferols) from cholesterol by specialised, tissue-specific mitochondrial enzymes [5]. 


\section{Mitochondrial genetics:}

Mitochondrial genetics is complicated by the contribution of two genomes: an intrinsic organellar genome encoding 37 genes and the extrinsic nuclear genome, which contributes $\sim 1500$ mitochondrially targeted gene products (i.e. 7\% of the nuclear exome is dedicated to providing the blueprints for mitochondrial proteins). The mitochondrial genome is a maternally inherited 16,569 base pair circular double-stranded DNA molecule encoding 13 OXPHOS subunits and the 2 ribosomal RNA (rRNA) and 22 transfer RNA (tRNA) molecules needed for the intramitochondrial synthesis of these 13 proteins on mitochondrial ribosomes. The nuclearencoded components of the 'mitochondrial proteome' include proteins needed for replication and maintenance of the mitochondrial genome and its expression (including numerous transcription and translation factors and $\sim 80$ ribosomal proteins), and proteins needed for import of proteins and solutes into the mitochondrion, as well as enzymes involved in the Krebs cycle, fatty acid beta oxidation and biosynthesis of cofactors and lipids including the steroid hormones [6].

Mutations of both genomes have now been linked to mitochondrial disease, including maternally inherited point mutations and sporadic large-scale rearrangements of the mitochondrial genome. Recently next generation sequencing methods have led to an enormous increase in nuclear gene defects linked to mitochondrial disease, with $>250$ gene defects already described [7]. The vast majority of these nuclear defects are recessive, although some of the late-onset disorders are caused by dominant mutations and a few are X-linked. Thus mitochondrial disease may exhibit any mode of inheritance: maternal, autosomal dominant, autosomal recessive, $\mathrm{X}$-linked or sporadic.

Mitochondrial genetics has some unusual properties. Mitochondrial DNA (mtDNA) is characterized by a very high copy number, with hundreds or thousands of copies in an individual cell, which in turn leads to the phenomena of homoplasmy (where $100 \%$ of the mtDNA copies within a cell are wild-type or mutant) and heteroplasmy (co-existence of mutant and wild-type mtDNA, ranging from 1 to $99 \%$ of the mutant mtDNA molecules) [8]. In the case of mtDNA mutations, in order for organ dysfunction to occur, a minimum critical proportion of mtDNA has to be mutated in a tissue before biochemical deficiency manifests [9]. Typically the most affected organs and tissues are those that are highly dependent on aerobic metabolism such as muscle, brain and heart. However, mutant heteroplasmy does not necessarily correlate with a patient's clinical manifestations. For example, evaluation of the amount of mutant mtDNA present in the sural nerve and thyroid gland of a patient with mitochondrial encephalomyopathy, lactic acidosis and stroke-like episodes (MELAS) showed >85\% heteroplasmy, without clinical dysfunction of these tissues [10]. 


\section{Consequences of mitochondrial dysfunction:}

Mitochondrial dysfunction has been reported in heterogeneous diseases and can theoretically involve any combination of organ systems, since mitochondria are present in all cells except mature erythrocytes [11]. Although some mitochondrial disorders only affect a single organ, most involve multiple organ systems with predominant neuromuscular and central nervous system features including ptosis, external ophthalmoplegia, proximal myopathy, seizures, ataxia, optic atrophy and sensorineural hearing loss, as well as cardiomyopathy and renal and hepatic impairment [1]. The incidence of endocrine dysfunction differs in various mitochondrial diseases, and appears to be most frequent in syndromes associated with large-scale rearrangements of the mtDNA. For example, in Kearns-Sayre syndrome (Table 1), the frequency of endocrine disturbance has been reported to range from $35 \%$ to $67 \%[12,13]$ Kearns-Sayre syndrome is characterized clinically by a triad of progressive external ophthalmoplegia and pigmentary retinopathy with age of onset $<20$ years, variably associated with cardiac conduction defects, cerebellar ataxia and other multisystem disease features. Other 'classical' mitochondrial syndromes include maternally inherited diabetes and deafness (MIDD), myoclonic epilepsy with ragged-red fibres (MERRF) and MELAS, all of which are associated with point mutations in the mitochondrial genome (Table 1).

Defective OXPHOS in mitochondrial diseases can lead to decreased intracellular production or extracellular secretion of hormones [14]. Impaired ATP synthesis decreases the activity of membrane bound calcium ATPase, leading to increased intracellular calcium (Figure 1). Reactive oxidative species (ROS) are by-products of energy generation, and require deactivation by antioxidant enzymes. ROS production is increased when OXPHOS is impaired and with deficient antioxidant defences. Since all steroid hormones are synthesised within mitochondria, lack of ATP may lead to impaired hormone production when there is mitochondrial dysfunction [5]. In the case of insulin, mitochondrial activity not only provides the necessary ATP required for insulin exocytosis, but mitochondria also play a central role in glucose-sensing and inducing triggering and amplifying signals to adjust insulin secretion to actual glycaemia [15]. Thus, multiple mechanisms may contribute to endocrine dysfunction in mitochondrial disease states (Table 2). The following sections will discuss dysfunction of each endocrine organ within the context of mitochondrial disease.

\section{Diabetes mellitus:}

Diabetes mellitus is the most well described form of endocrine dysfunction in mitochondrial diseases. The association between mitochondrial disease and diabetes is best characterized in MIDD, a syndrome caused by the 'common' mtDNA point mutation m.3243A>G in the MT-TL1 gene encoding a mitochondrial tRNA for leucine. This mutation is also associated with MELAS and is present in 1 in 400 people, although the majority are asymptomatic or oligosymptomatic. The m.3423A $>\mathrm{G}$ mutation is estimated to cause $\sim 0.5$ to $2.8 \%$ of all cases of diabetes, more 
commonly in Japanese patients [9, 16-19], making MIDD the most frequently reported mitochondrial diabetes in the literature. Diabetes and multiple endocrinopathies are also observed in Kearns-Sayre syndrome caused by large-scale mtDNA rearrangements [20, 21]. Other mtDNA mutations associated with diabetes include point mutations in the tRNA genes MT-TL1 (m.3254C>G, m.3256C >T, m.3264T>G, m.3271T>C), MT-TK (m.8344A>G, m.8356T>C), MT-TS2 (m.12258T >C) and MT-TE (m.14709T $>C$ ), as well as the m.14577T $>C$ mutation in the complex I subunit ND6 [18, 20-22]. Diabetes mellitus has also been reported in nuclearencoded mitochondrial diseases caused by autosomal recessive mutations in POLG, RRM2B, OPA1 and MPV17, all genes implicated in mtDNA maintenance [9, 20, 23, 24].

Mitochondrial diabetes can present as type I or type II diabetes [16], and can present insidiously at any age, but with an average age of onset of 38 years for the common m.3243A>G mutation, and ranging from 40 to 56 years for other mutations [21]. Previous studies suggest that insulin deficiency plays a major role in development of diabetes, owing to progressive loss of beta-cells within the pancreas. The mechanism leading to mitochondrial dysfunction by the m.3243A>G mutation is a reduction of synthesis of mtDNA-encoded proteins, leading to an imbalance within the mitochondrion between nuclear and mitochondrial-encoded OXPHOS subunits [25, 26]. More recent studies demonstrated a combined insulin deficiency and insulin resistance in individuals with m.3243A>G and diabetes $[27,28]$. Individuals with mitochondrial diabetes exhibit a high risk of progression to insulin dependency, unlike other forms of type 2 diabetes. This provides further support for the theory of a combined insulin deficiency and resistance. In two studies only $13 \%$ of diabetic patients with $\mathrm{m} .3243 \mathrm{~A}>\mathrm{G}$ required insulin at presentation, with $\sim 45 \%$ progressing to insulin dependence after a mean interval of 4.2 years in the first study [21] and 10 years in the second [29].

Pancreatic exocrine insufficiency is a frequent feature of Pearson syndrome (Table 1), an earlyonset mtDNA deletion disorder. Insulin-dependent diabetes mellitus in infancy has been described in some patients, with or without concurrent exocrine pancreatic insufficiency [12]. Onset of diabetes ranged from the neonatal period to 21 months [30-32]. Autopsy revealed fibrosis and atrophy of the exocrine and endocrine pancreas in two cases [31, 32], and hypoplasia of the pancreas in one case with diabetes but without symptoms suggestive of malabsorption [12].

Pattern recognition and a high level of suspicion are crucial to identifying patients with mitochondrial disease. Multi-systemic disease manifestations may precede onset of diabetes. Other organs with high metabolic activity are usually affected, including the brain, muscles, myocardium and kidneys. As in MIDD, a combination of sensorineural deafness and a family history of maternal inheritance should raise suspicion. Hearing loss usually develops in early adulthood (range 2-61 years) [29]. The most common ophthalmic feature is macular retinal dystrophy, observed in $86 \%$ of adult patients in a multicentre prospective study of MIDD [29]. Other clues pointing towards mitochondrial diabetes include a lower than average BMI [21, 33]. 
Patients with m.3243A>G have not been found to carry islet cell or GAD antibodies [9], and the phenotype of diabetes in MIDD appears to be independent of HLA-DQ phenotype [34].

With regards to the complications of diabetes, retinopathy, neuropathy and renal failure were more prevalent in a cohort of patients with m.3243A>G compared to patients with type 1 or 2 diabetes in the UK [21]. Cardiac manifestations were also more frequent in MIDD patients with diabetes compared with other diabetic patients. This includes left ventricular hypertrophy in absence of hypertension, cardiac autonomic neuropathy and reduced heart rate variability without coronary artery disease [35-38]. This implies that pre-existent mitochondrial dysfunction in the end organs predispose to these macro and microvascular complications [9, 21].

As aforementioned, patients usually present with non-insulin dependent diabetes, but a significant proportion of patients rapidly progress to insulin dependency. The drug of choice for non-insulin dependent diabetes is sulphonylurea [9]. Metformin and thiazolidinediones should ideally be avoided since they inhibit mitochondrial complex I and may worsen lactic acidosis $[20,39,40]$. End organ involvement should be carefully monitored. With the high risk of renal involvement, early use of angiotensin-converting enzyme inhibitors in case of renal involvement and a tight control of hypertension is recommended [18]. Statins should be used judiciously in view of their potential for inducing myositis. Monitoring creatine kinase levels pre and post treatment is recommended during statin treatment [9].

\section{Short stature and growth hormone deficiency}

Short stature is commonly described in mitochondrial diseases, and was a presenting feature in $48 \%$ of a cohort of 96 MELAS patients in Japan [41]. Fifty-five percent of patients developed short stature during their disease course. As might be expected, short stature was a more common presenting symptom in patients with juvenile-onset MELAS compared to adult-onset MELAS (60\% versus 29\%). Review of height and weight data of 24 children and adolescents with a confirmed diagnosis of mitochondrial disease revealed short stature (overall height SDS -1.97; $95 \%$ confidence intervals -2.72 to -1.23 ), and a lower body mass index (SDS $-1.07 ; 95 \%$ confidence intervals -1.69 to - 0.07) [42]. Faltering growth was also noted in $28 \%$ of the Japanese MELAS cohort [41]. Whilst short stature may arise from any severe mitochondrial disease with onset in infancy or early childhood, it has been reported most frequently in association with cytochrome oxidase (complex IV) deficiency, including mutations in the NDUFA4 subunit and the assembly factors SURF1, COX10 and LRPPRC [43-46]. Growth failure was reported in $95 \%$ of patients in a multicentre cohort of children with Leigh syndrome secondary to SURF1 deficiency (complex IV assembly defect) [45], compared to $52 \%$ of patients with Leigh syndrome caused by LRPPRC mutations (leading to impaired mitochondrial translation of a complex IV subunit) [46]. Short stature is also recognised in Kearns-Sayre 
syndrome, with reported rates ranging from $38 \%$ to $63 \%[47,48]$. However, the precise mechanism for growth failure has not been well established.

Growth hormone deficiency has been described in multiple case reports and case series with MELAS [10, 49-53], decreased complex II activity [54], mtDNA deletion disorders [12, 13, 55-58], and various mitochondrial diseases without genetic confirmation [59,60]. Growth hormone deficiency and/or short stature has also been documented in nuclear-encoded defects of mitochondrial translation, e.g. mutations in IARS2, MTFMT and C12orf65 [61-63] .

Hypothalamo-pituitary dysfunction has been proposed as the mechanism for growth hormone deficiency in mitochondrial disease. Previous hypotheses for hypothalamic dysfunction include chronic ischaemia and energy deficiency of the diencephalon due to mitochondrial abnormality of the region [51]. One MELAS patient with growth hormone deficiency had high (95\%) levels of mutant mtDNA in the hypophysis [10]. This patient also had anterior pituitary dysfunction in addition to hypothalamic impairment. Non-specific degenerative changes and cerebral atrophy were reported in patients with mitochondrial disease and growth hormone deficiency [10, 13, 50]. The pituitary gland was described to be normal despite severe cerebral and cerebellar atrophy in one patient with MELAS presenting with multiple endocrinopathies suggestive of hypothalamic dysfunction [50]. In contrast, the only MRI abnormality observed in a 10 year old boy with MELAS and complete growth hormone deficiency was bilateral T2-weighted hyperintense signal in the globus pallidus and in the midbrain tegment [57].

Most patients reported with confirmed growth hormone deficiency were started on growth hormone treatment, and short term improvement in growth has been noted without adverse effects $[12,49,54,56,59,60]$. However long term effects of growth hormone in this population are not clear [64]. Although most described patients did not suffer any adverse effects from growth hormone treatment, Romano et al [60] reported two patients whose condition worsened on growth hormone treatment, of which one patient did not have growth hormone deficiency. One patient developed hypotonia, loss of language and memory skills, and the other developed severe hypotonia, cerebellar ataxia and loss of speech and pyramidal signs after three months of treatment. Both patients showed improvement in their condition with discontinuation of growth hormone therapy. This was hypothesized to be due to the fact that growth hormone is a stimulator of mitosis, and may increase energy demand for cell proliferation. However, it is difficult to draw firm conclusions on such small numbers. There are also reports of patients with growth hormone deficiency who did not respond to growth hormone treatment $[60,65]$.

Growth hormone deficiency has not been identified in some mitochondrial patients with short stature $[13,60,66]$. Many patients have delayed or absent puberty, and this is also thought to be contributory to the reported short stature, especially if they present during adolescence.

In summary, short stature is a common feature of mitochondrial disease, and growth hormone deficiency has been well described, particularly in mtDNA deletion syndromes and MELAS. 
However, many patients with short stature do not have growth hormone deficiency. Brain imaging findings are non-specific in growth hormone deficient patients, and have not been reported to show pituitary abnormalities. Growth hormone therapy has been effective in improving height gain in some patients without adverse effects. However, efficacy is variable and in view of potential adverse effects in this condition, growth hormone should be used with caution and close monitoring is recommended.

\section{Hypogonadism:}

Both hypergonadotrophic and hypogonadotrophic hypogonadism have been described in patients with mitochondrial disease. Thirty-eight percent of a cohort of 21 patients with mitochondrial myopathy and external ophthalmoplegia were reported to have various signs of hypogonadism [13]. Hypergonadotrophic hypergonadism can also occur due to specific mitochondrial steroidogenic defects affecting the testis or ovary (e.g. STAR, CYP11A1, HSD3B2 mutations) but detailed discussion of these conditions is beyond the scope of this review.

Hypogonadotrophic hypogonadism due to hypothalamic dysfunction has been more frequently described than primary ovarian or testicular insufficiency in patients with MELAS, MERRF and Kearns-Sayre syndromes. Poor development of secondary sexual characteristics and low serum LH and FSH concentrations have been reported [13, 53, 67-70]. Not all cases had delayed pubertal onset. Some form of pubertal development appeared to have occurred in these patients, who subsequently developed oligomenorrhoea or secondary amenorrhoea. Primary ovarian insufficiency was excluded in some of these cases [13].

Hypergonadotrophic hypogonadism has been described in mtDNA depletion syndrome caused by mutations in C10orf2 (encoding the twinkle DNA helicase) [71]. Two of 23 patients with infantile onset spinocerebellar ataxia (IOSCA) caused by recessive C10orf2 mutations, both compound heterozygotes for the p.Y508C and p.A318T mutations, were noted to have hypergonadotrophic hypogonadism by teenage years alongside their neurological symptoms [71]. Other mitochondrial causes of hypergonadotrophic hypogonadism include POLG mutations [72-74], mitochondrial neurogastrointestinal encephalomyopathy (MNGIE) [75], primary coenzyme $Q_{10}$ deficiency [76], Leigh syndrome caused by $L R P P R C$ mutation [46], and one patient with mutations in MRPS7 encoding a mitochondrial ribosomal protein [77]. A novel "ovarioleukodystrophy" has been linked to mutations in AARS2 (encoding mitochondrial alanyltRNA synthetase), where all females with late-onset disease present with ovarian insufficiency, followed by progressive leukoencephalopathy [78]. Thus all nuclear-encoded defects causing hypergonadotrophic hypogonadism appear to be associated with impaired mtDNA maintenance or gene expression.

Mitochondrial primary ovarian insufficiency and premature menopause have been described most frequently in patients with the dominantly inherited POLG mutation p.Y955C, including 
four women with progressive external ophthalmoplegia and early menopause before the age of 35 years and a three generation pedigree with progressive external ophthalmoplegia and premature ovarian insufficiency $[72,73]$. Other POLG mutations associated with primary ovarian insufficiency in single cases include p.N468D/p.A1105T [72], p.R943H [74] and p.R953C [79]. Of note, all the patients had accompanying neurological features.

The occurrence of ovarian mtDNA deletion and menstrual irregularity has been observed in menopausal women [80]. The mature oocyte has the highest mtDNA copy of all cells [81], and is likely to be more sensitive than other tissues to a reduced DNA polymerase gamma activity [73]. An inadequate pool of primordial follicles, impaired oocyte maturation and accelerated follicle apoptosis due to dysfunction of cytochrome oxidase and increased ROS production have all been hypothesized to be the cause of ovarian insufficiency in the aging oocyte [82, 83]. Two studies aimed to elucidate whether POLG mutations could be responsible for isolated primary ovarian insufficiency in a more general population. Tong et al [79] evaluated $20146, X X$ women with ovarian insufficiency for five common POLG mutations associated with ovarian insufficiency, and found only one with a POLG mutation (p.R943H), whilst Duncan et al did not identify any of four common POLG mutations in a cohort of 57 women with premature ovarian insufficiency [84]. Thus, POLG mutations do not appear to be a common genetic aetiology for this form of infertility. Moreover, almost all women had associated neurological features, suggesting that POLG mutation testing is only indicated where there is clinical suspicion of a possible mitochondrial disorder.

Perrault syndrome is characterised by ovarian dysgenesis and sensorineural deafness [85]. Biallelic pathogenic variants have now been reported in five genes in individuals with Perrault syndrome. Although the first reported gene HSD17B4 encodes a peroxisomal enzyme (17-beta hydroxysteroid dehydrogenase type 4 , involved in fatty acid beta-oxidation and steroid metabolism), the remaining four encode mitochondrial proteins. Three of these are involved in maintenance and expression of the mitochondrial genome: C10orf2 [86], HARS2 (encoding mitochondrial histidyltRNA synthetase), and LARS2 (encoding mitochondrial leucyl-tRNA synthetase) $[85,87-90]$. The fifth gene, CLPP, encodes a serine protease that is an important component of the mitochondrial quality control system. Associated neurological symptoms in patients with CLPP mutations include truncal and cerebellar ataxia and lower limb spasticity [89]. Patients with LARS2 mutations had apparently normal neurology and intelligence [88].

Mitochondrial dysfunction has been less frequently linked to male fertility in the literature. Both hypogonadotrophic and hypergonadotrophic hypogonadism have been described in male patients with MNGIE $[69,75]$. It was postulated that POLG mutations might be a cause of male infertility, but more recent studies have not confirmed an association between POLG mutations and oligo-azoospermia [91-93]. There was no testicular dysfunction in male patients with Perrault syndrome or AARS2 mutations, despite the presence of ovarian insufficiency in female patients with the same mutations $[78,88]$. 
In summary, hypogonadism may occur in patients with mitochondrial disease, manifesting either as hypothalamic dysfunction or as end organ insufficiency. Primary ovarian insufficiency may be the presenting feature of mitochondrial disease, preceding onset of neurological symptoms.

\section{Adrenal dysfunction:}

Mitochondrial abnormalities of the adrenal axis were initially described in mtDNA deletion syndromes such as Kearns-Sayre and Pearson syndromes. A total of 12 case reports identified primary adrenal insufficiency in 14 patients with genetically confirmed mitochondrial disease [94], of whom five had Kearns-Sayre syndrome [14, 95-98], and two Pearson syndrome [30, 99]. More recently primary adrenal insufficiency was reported in a child with a MELAS phenotype, atypically associated with the m.8344A>G mutation, more commonly linked to MERRF syndrome [100].

Several nuclear-encoded mitochondrial defects are associated with adrenal dysfunction. However, since these do not primarily affect OXPHOS and a detailed review of these conditions is provided elsewhere [5], they will only be discussed briefly here. Mutations in STAR (encoding steroidogenic acute regulatory protein) affect cholesterol transport across the mitochondrial membrane and defects in CYP11A1 (encoding P450 cholesterol side chain cleavage) affect pregnenolone production. Severe defects in both these factors cause early-onset adrenal insufficiency, often with impaired gonadal sex steroid production. However, milder forms can present with isolated adrenal insufficiency in childhood [101]. Other steroidogenic enzymes localised to the mitochondria are $3 \beta$-hydroxysteroid dehydrogenase, $11 \beta$-hydroxylase and aldosterone synthase, which are involved in mineralocorticoid synthesis. More recently mutations in NNT, an antioxidant defence gene encoding nicotinamide nucleotide transhydrogenase, and TXNRD2, encoding thioredoxin reductase 2 (also part of the mitochondrial antioxidant defence system), have been associated with familial glucocorticoid deficiency $[102,103]$. In view of the severe nature of these defects, it is somewhat surprising that the only clinical manifestation was isolated glucocorticoid deficiency. Further studies are needed to determine why the adrenal gland appears to be particularly susceptible to oxidative stress and whether any other clinical features develop with time [104].

Other nuclear-encoded defects associated with adrenal insufficiency include defective complex I assembly caused by NDUFAF5 mutations [105], and abnormalities of mitochondrial translation, import and mtDNA replication. One of two sisters with mutations in the MRPS7 mitochondrial ribosomal subunit had primary adrenal insufficiency and primary hypogonadism at 16 years [77], and adrenal insufficiency was also reported in a patient with combined respiratory complex deficiencies due to a homozygous QRSL1 mutation [7]. A 19 year old woman with mitochondrial encephalopathy caused by mutations in GFER, encoding a component of the mitochondrial protein import system, had primary adrenal insufficiency 
associated with congenital cataracts and lactic acidosis [94]. Finally, identical twins with a multisystem disorder, including polyendocrinopathy (diabetes, adrenal insufficiency and hypothyroidism), bilateral basal ganglia infarcts, headaches, seizures and psychiatric problems, were reported to have a heterozygous POLG mutation p.G517V [23]. However, it has since been suggested that p.G517V is a neutral polymorphism [106], so the underlying cause of mitochondrial disease in this family remains unclear.

Adrenal insufficiency with hyperpigmentation and hyponatraemia can be the first presenting symptom prior to onset of other symptoms such as neurological symptoms, deafness and other endocrine dysfunction [100,107]. However, age at onset of adrenal insufficiency varies widely, ranging from 7 months to 32 years, and can be preceded by other disease features.

Impaired mitochondrial ATP production and/or oxidative stress are the most likely explanations for the decreased capacity of adrenocortical hormone production. A limited autopsy was performed in one case and showed a trace amount of scar tissue replacing the adrenal glands [96]. Although adrenal insufficiency was a dominant feature in this patient, the mutant load was only $65 \%$ in the adrenal glands, compared to $95 \%$ in the liver, without any clinical hepatic disease. Thus, the degree of mutant heteroplasmy among tissues does not necessarily correlate with clinical manifestations.

Interestingly, hypothalamic-pituitary dysfunction as a cause of secondary cortisol insufficiency has only been reported once in a case with MERRF [108]. Growth hormone and gonadotrophins appear to be the predominant hormonal deficits in mitochondrial patients with pituitary or hypothalamic dysfunction.

\section{Hypoparathyroidism:}

Hypoparathyroidism, although not common, is well recognized in mitochondrial diseases in particular Kearns-Sayre syndrome. In a literature survey conducted in 1992, Harvey et al retrospectively reviewed endocrine dysfunction in 226 cases fitting the criteria for Kearns-Sayre syndrome [48]. Fourteen of $226(6 \%)$ of cases had hypoparathyroidism, although a mixture of probable cases and a small number of cases with onset after the age of 20 years were included. In a more recent series three of 34 (9\%) of children with single mtDNA deletion disorders had hypoparathyroidism [12]. In two Kearns-Sayre patients with hypoparathyroidism, one patient had absent glands at autopsy [109], and the other had only one gland confirmed by microscopic examination [110]. Four children with Kearns-Sayre syndrome presented hypoparathyroidism and deafness as initial major manifestations, with hypocalcaemic tetany starting between 6 and 13 years [111]. Deafness preceded the onset of hypoparathyroidism in two patients. Hypoparathyroidism was the initial presentation at age three years, prior to onset of growth failure and hearing deficit, in another case [112]. Other patients had other accompanying 
features including growth failure and neurological symptoms, ptosis, ophthalmoplegia, myopathy and sensorineural hearing loss.

Renal tubulopathy is common in patients with Kearns-Sayre disease, leading to significant calcium, magnesium and potassium losses in the urine. Severe hypomagnesaemia suppresses parathyroid hormone secretion and may induce some parathyroid hormone resistance, leading to further hypocalcaemia [113]. Parathyroid hormone concentrations remained low despite magnesium supplementation in two cases $[114,115]$. Co-existing renal tubular dysfunction and hypoparathyroidism may contribute to disturbances in calcium homeostasis in patients with Kearns-Sayre syndrome.

Apart from Kearns-Sayre syndrome, hypoparathyroidism has been documented in one patient with MIDD with the classical m.3243A>G mutation [116].

Multiple endocrinopathies have been documented in case reports of patients with Kearns-Sayre syndrome with hypoparathyroidism, in particular in association with diabetes mellitus [111, $112,117,118]$. Hypoparathyroidism appears to be rare in adult forms of mitochondrial disease, and seems most likely to occur in severely affected patients who present with multi-systemic disease in childhood [9]. The authors hypothesized that the heteroplasmic threshold for dysfunction of the parathyroid gland is only reached in cases where very high levels of heteroplasmy are present in most tissues. The incidence of other endocrine abnormalities also appeared to be more frequent in patients with hypoparathyroidism, including diabetes mellitus ( $28 \%$ versus $12 \%$ ), thyroid disease ( $14 \%$ versus $2 \%$ ) and hypogonadism (35\% versus $18 \%$ ), however the sample sizes were too small to reach robust conclusions [48].

In summary mitochondrial hypoparathyroidism is associated with severe multisystem disease and is often seen in combination with other endocrinopathies in Kearns-Sayre syndrome.

\section{Thyroid disease:}

Thyroid dysfunction has been infrequently reported in mitochondrial disease, and the prevalence appears to be similar to the background population rate [9]. However, numerous case reports have documented hypothyroidism developing in a heterogeneous group of patients, including 15\% (6 out of 40) of an adult cohort with late onset chronic progressive external ophthalmoplegia, and was more frequent than diabetes mellitus (5\%) in this cohort [119]. Hypothyroidism has been described in patients with mtDNA deletions including KearnsSayre syndrome $[12,48,55]$. In the literature review by Harvey et al in 1992, 7 of 226 cases (3\%) with probable Kearns-Sayre syndrome had thyroid disease [48]. Types of thyroid dysfunction reported include compensated hypothyroidism, multinodular goitre, congenital thyroid malformation, and one patient with papillary carcinoma. Central hypothyroidism has been described in a patient with MELAS [53]. 
Very few nuclear-encoded mitochondrial defects have been linked to thyroid dysfunction. As discussed above, a polyendocrinopathy including diabetes, adrenal insufficiency and hypothyroidism was reported in twins with a heterozygous POLG mutation p.G517V [23], but the pathogenic significance of this mutation has since been questioned [106]. Recently recessive mutations in $P T R H 2$, encoding mitochondrial peptidyl-tRNA hydrolase 2, have been associated with a complex multisystem disorder including hypothyroidism and exocrine pancreatic insufficiency, associated with intellectual disability, microcephaly, progressive ataxia, distal muscle weakness, peripheral demyelinating sensorimotor neuropathy, growth retardation, sensorineural deafness and liver fibrosis [120].

In summary, thyroid dysfunction is common in the general population, and it is currently unknown whether there is any causal relationship between mitochondrial disease and thyroid dysfunction. There are inadequate data to suggest whether thyroid dysfunction occurs more frequently in mitochondrial disease compared to the background population. However, as subclinical hypothyroidism can be asymptomatic, the incidence of hypothyroidism is probably underestimated in this group of patients.

\section{Conclusions:}

Mitochondrial diseases are multi-systemic diseases, and can present with endocrine dysfunction, in particular in the mtDNA deletion syndromes such as Kearns-Sayre syndrome and disorders associated with mtDNA point mutations affecting tRNA genes, such as MIDD, MELAS and MERRF. Recently endocrine dysfunction has been reported in a large number of nuclearencoded mitochondrial defects, particularly those affecting maintenance of mtDNA or mitochondrial translation. The underlying disease mechanisms leading to mitochondrial endocrine dysfunction remain obscure. Failure to synthesise and/or secrete hormones secondary to lack of ATP and/or oxidative stress have been implicated, but other possible mechanisms include impaired cellular signalling and calcium handling. Further studies in animal and patient cell models of mitochondrial disease are needed in order to tease out these mechanisms in more detail.

Diabetes mellitus is well recognized in mitochondrial diseases, especially in the MIDD syndrome. Gonadal insufficiency, in particular ovarian insufficiency, has also been reported in various mitochondrial disorders. Other end organ dysfunction such as primary adrenal insufficiency and hypoparathyroidism are less frequently described. Multiple endocrinopathies can include hypothalamic dysfunction with multiple pituitary hormone deficiencies. Patients with hypoparathyroidism and primary adrenal insufficiency have also been found to have other endocrinopathies.

Endocrine dysfunction can sometimes be the initial presenting symptom preceding hearing impairment and other neurological manifestations of mitochondrial diseases. Physicians should 
have a high level of suspicion in patients presenting with endocrine abnormalities and multisystemic diseases for the possibility of an underlying mitochondrial disease (Figure 3). In parallel, physicians managing patients with mitochondrial diseases should be aware of possible multiple endocrine complications and regularly screen for them in at risk patients, since these are potentially treatable aspects of these incurable disorders.

\section{Acknowledgements:}

We thank Aziza Khabbush for assistance with the artwork. S.R. is supported by Great Ormond Street Hospital Children's Charity and currently receives research grant funding from The Wellcome Trust, The Lily Foundation, and Vitaflo International Ltd. J.C.A. is a Wellcome Trust Senior Research Fellow in Clinical Science [098513]. J.C.A., M.T.D. and S.R. all receive support from the National Institute for Health Research Biomedical Research Centre at Great Ormond Street Hospital for Children NHS Foundation Trust and University College London.

\section{Author details:}

\section{Jasmine Chow}

Dr Jasmine Chow is an associate consultant in the Department of Paediatrics at Queen Elizabeth Hospital in Hong Kong. She trained in general paediatrics in Hong Kong and is a Fellow of the Hong Kong College of Paediatrics and Child Health. She has a special interest in endocrinology and inborn errors of metabolism, and has trained in both fields at Great Ormond Street Hospital for Children, UK, and Baylor College of Medicine, USA.

\section{Joyeeta Rahman}

Joyeeta Rahman is a Canadian third year BSc (Hons) student in Biomedical Sciences at University College London.

\section{John C. Achermann}

Professor John Achermann trained in paediatric endocrinology and molecular genetics in Cambridge, UK, London, UK, and Chicago, USA. He is currently a Wellcome Trust Senior Research Fellow in Clinical Science, Professor of Paediatric Endocrinology at UCL Institute of Child Health and Honorary Consultant at Great Ormond Street Hospital for Children NHS Foundation Trust, UK. His main research interests are adrenal and sex development, human genetics and nuclear receptor biology.

\section{Mehul T. Dattani}


Professor Mehul Dattani is Professor of Paediatric Endocrinology based at the UCL Institute of Child Health, and Head of Paediatric Endocrinology at Great Ormond Street Hospital for Children (GOSH). He has an active clinical practice encompassing all areas of paediatric and adolescent endocrinology at GOSH and University College London Hospitals (UCLH). He is also Head of the Genetics and Epigenetics in Health and Disease (GEHD) section within the Genetics and Genomic Medicine Programme at $\mathrm{ICH}$. His research interests lie in the area of rare endocrine disorders, particularly the molecular basis of disorders affecting the hypothalamopituitary axis.

\section{Shamima Rahman}

Professor Shamima Rahman trained in medicine at Oxford University, UK, and in paediatric metabolic medicine at Great Ormond Street Hospital, London, UK. She is a Professor of Paediatric Metabolic Medicine at UCL Institute of Child Health and Honorary Consultant at Great Ormond Street Hospital for Children NHS Foundation Trust, UK. Her research focusses on discovery of the molecular basis of mitochondrial diseases and development of novel therapies for these currently incurable disorders. She is an Editor of the Journal of Inherited Metabolic Disease and a member of the Education and Training Advisory Committee of the Society for the Study of Inborn Errors of Metabolism.

\section{References:}

1. Chinnery, P.F., Mitochondrial Disorders Overview, in GeneReviews(R), R.A. Pagon, et al., Editors. 1993: Seattle (WA).

2. Thorburn, D.R., Mitochondrial disorders: prevalence, myths and advances. J Inherit Metab Dis, 2004. 27(3): p. 349-62.

3. Pagano, G., et al., Oxidative stress and mitochondrial dysfunction across broad-ranging pathologies: toward mitochondria-targeted clinical strategies. Oxid Med Cell Longev, 2014. 2014: p. 541230.

4. Stark, R. and M. Roden, ESCI Award 2006. Mitochondrial function and endocrine diseases. Eur J Clin Invest, 2007. 37(4): p. 236-48.

5. Miller, W.L., Steroid hormone synthesis in mitochondria. Mol Cell Endocrinol, 2013. 379(1-2): p. 62-73.

6. Calvo, S.E., K.R. Clauser, and V.K. Mootha, MitoCarta2.0: an updated inventory of mammalian mitochondrial proteins. Nucleic Acids Res, 2016. 44(D1): p. D1251-7.

7. Kohda, M., et al., A Comprehensive Genomic Analysis Reveals the Genetic Landscape of Mitochondrial Respiratory Chain Complex Deficiencies. PLoS Genet, 2016. 12(1): p. e1005679.

8. Payne, B.A., et al., Universal heteroplasmy of human mitochondrial DNA. Hum Mol Genet, 2013. 22(2): p. 384-90.

9. Schaefer, A.M., et al., Endocrine disorders in mitochondrial disease. Mol Cell Endocrinol, 2013. 379(1-2): p. 2-11. 
10. Shiraiwa, N., et al., Content of mutant mitochondrial DNA and organ dysfunction in a patient with a MELAS subgroup of mitochondrial encephalomyopathies. J Neurol Sci, 1993. 120(2): p. 174-9.

11. Munnich, A., et al., Clinical presentation of mitochondrial disorders in childhood. J Inherit Metab Dis, 1996. 19(4): p. 521-7.

12. Broomfield, A., et al., Paediatric single mitochondrial DNA deletion disorders: an overlapping spectrum of disease. J Inherit Metab Dis, 2015. 38(3): p. 445-57.

13. Quade, A., S. Zierz, and D. Klingmuller, Endocrine abnormalities in mitochondrial myopathy with external ophthalmoplegia. Clin Investig, 1992. 70(5): p. 396-402.

14. Sanaker, P.S., et al., Clinical evolution of Kearns-Sayre syndrome with polyendocrinopathy and respiratory failure. Acta Neurol Scand Suppl, 2007. 187: p. 64-7.

15. Maechler, P., Mitochondrial function and insulin secretion. Mol Cell Endocrinol, 2013. 379(1-2): p. 12-8.

16. Maassen, J.A., et al., Mitochondrial diabetes: molecular mechanisms and clinical presentation. Diabetes, 2004. 53 Suppl 1: p. S103-9.

17. Ohkubo, K., et al., Mitochondrial gene mutations in the tRNA(Leu(UUR)) region and diabetes: prevalence and clinical phenotypes in Japan. Clin Chem, 2001. 47(9): p. 1641-8.

18. Murphy, R., et al., Clinical features, diagnosis and management of maternally inherited diabetes and deafness (MIDD) associated with the 3243A>G mitochondrial point mutation. Diabet Med, 2008. 25(4): p. 383-99.

19. Kishimoto, M., et al., Diabetes mellitus carrying a mutation in the mitochondrial tRNA(Leu(UUR)) gene. Diabetologia, 1995. 38(2): p. 193-200.

20. Karaa, A. and A. Goldstein, The spectrum of clinical presentation, diagnosis, and management of mitochondrial forms of diabetes. Pediatr Diabetes, 2015. 16(1): p. 1-9.

21. Whittaker, R.G., et al., Prevalence and progression of diabetes in mitochondrial disease. Diabetologia, 2007. 50(10): p. 2085-9.

22. Mancuso, M., et al., Phenotypic heterogeneity of the $8344 A>G$ mtDNA "MERRF" mutation. Neurology, 2013. 80(22): p. 2049-54.

23. Hopkins, S.E., A. Somoza, and D.L. Gilbert, Rare autosomal dominant POLG1 mutation in a family with metabolic strokes, posterior column spinal degeneration, and multi-endocrine disease. J Child Neurol, 2010. 25(6): p. 752-6.

24. Garone, C., et al., MPV17 Mutations Causing Adult-Onset Multisystemic Disorder With Multiple Mitochondrial DNA Deletions. Arch Neurol, 2012. 69(12): p. 1648-51.

25. Janssen, G.M., J.A. Maassen, and J.M. van Den Ouweland, The diabetes-associated 3243 mutation in the mitochondrial tRNA(Leu(UUR)) gene causes severe mitochondrial dysfunction without a strong decrease in protein synthesis rate. J Biol Chem, 1999. 274(42): p. 29744-8.

26. Maassen, J.A., et al., Mitochondrial diabetes and its lessons for common Type 2 diabetes. Biochem Soc Trans, 2006. 34(Pt 5): p. 819-23.

27. El-Hattab, A.W., et al., Glucose metabolism derangements in adults with the MELAS m.3243A>G mutation. Mitochondrion, 2014. 18: p. 63-9.

28. Lindroos, M.M., et al., Mitochondrial diabetes is associated with insulin resistance in subcutaneous adipose tissue but not with increased liver fat content. J Inherit Metab Dis, 2011. 34(6): p. 1205-12.

29. Guillausseau, P.J., et al., Maternally inherited diabetes and deafness: a multicenter study. Ann Intern Med, 2001. 134(9 Pt 1): p. 721-8.

30. Williams, T.B., et al., Pearson syndrome: unique endocrine manifestations including neonatal diabetes and adrenal insufficiency. Mol Genet Metab, 2012. 106(1): p. 104-7. 
31. Superti-Furga, A., et al., Pearson bone marrow-pancreas syndrome with insulin-dependent diabetes, progressive renal tubulopathy, organic aciduria and elevated fetal haemoglobin caused by deletion and duplication of mitochondrial DNA. Eur J Pediatr, 1993. 152(1): p. 44-50.

32. Morikawa, Y., et al., Pearson's marrow/pancreas syndrome: a histological and genetic study. Virchows Arch A Pathol Anat Histopathol, 1993. 423(3): p. 227-31.

33. Guillausseau, P.J., et al., Heterogeneity of diabetes phenotype in patients with 3243 bp mutation of mitochondrial DNA (Maternally Inherited Diabetes and Deafness or MIDD). Diabetes Metab, 2004. 30(2): p. 181-6.

34. van Essen, E.H., et al., HLA-DQ polymorphism and degree of heteroplasmy of the A3243G mitochondrial DNA mutation in maternally inherited diabetes and deafness. Diabet Med, 2000. 17(12): p. 841-7.

35. Majamaa-Voltti, K., et al., Cardiac abnormalities in patients with mitochondrial DNA mutation 3243A>G. BMC Cardiovasc Disord, 2002. 2: p. 12.

36. Momiyama, Y., et al., Cardiac autonomic nervous dysfunction in diabetic patients with a mitochondrial DNA mutation: assessment by heart rate variability. Diabetes Care, 2002. 25(12): p. 2308-13.

37. Momiyama, Y., et al., Left ventricular hypertrophy and diastolic dysfunction in mitochondrial diabetes. Diabetes Care, 2001. 24(3): p. 604-5.

38. Wahbi, K., et al., Long-term cardiac prognosis and risk stratification in 260 adults presenting with mitochondrial diseases. Eur Heart J, 2015.

39. Ghosh, S., et al., The thiazolidinedione pioglitazone alters mitochondrial function in human neuron-like cells. Mol Pharmacol, 2007. 71(6): p. 1695-702.

40. Brunmair, B., et al., Thiazolidinediones, like metformin, inhibit respiratory complex I: a common mechanism contributing to their antidiabetic actions? Diabetes, 2004. 53(4): p. 1052-9.

41. Yatsuga, S., et al., MELAS: a nationwide prospective cohort study of 96 patients in Japan. Biochim Biophys Acta, 2012. 1820(5): p. 619-24.

42. Wolny, S., et al., Abnormal growth in mitochondrial disease. Acta Paediatr, 2009. 98(3): p. 553-4.

43. Pitceathly, R.D., et al., NDUFA4 mutations underlie dysfunction of a cytochrome c oxidase subunit linked to human neurological disease. Cell Rep, 2013. 3(6): p. 1795-805.

44. Pitceathly, R.D., et al., COX10 mutations resulting in complex multisystem mitochondrial disease that remains stable into adulthood. JAMA Neurol, 2013. 70(12): p. 1556-61.

45. Wedatilake, Y., et al., SURF1 deficiency: a multi-centre natural history study. Orphanet J Rare Dis, 2013. 8: p. 96.

46. Debray, F.G., et al., LRPPRC mutations cause a phenotypically distinct form of Leigh syndrome with cytochrome c oxidase deficiency. J Med Genet, 2011. 48(3): p. 183-9.

47. Berenberg, R.A., et al., Lumping or splitting? "Ophthalmoplegia-plus" or Kearns-Sayre syndrome? Ann Neurol, 1977. 1(1): p. 37-54.

48. Harvey, J.N. and D. Barnett, Endocrine dysfunction in Kearns-Sayre syndrome. Clin Endocrinol (Oxf), 1992. 37(1): p. 97-103.

49. Matsuzaki, M., et al., Hypothalamic growth hormone deficiency and supplementary GH therapy in two patients with mitochondrial myopathy, encephalopathy, lactic acidosis and stroke-like episodes. Neuropediatrics, 2002. 33(5): p. 271-3.

50. Joko, T., et al., A case of mitochondrial encephalomyopathy, lactic acidosis and stroke-like episodes associated with diabetes mellitus and hypothalamo-pituitary dysfunction. Endocr J, 1997. 44(6): p. 805-9.

51. Matsuzaki, M., et al., [Hypothalamic GH Deficiency and gelastic seizures in a 10-year-old girl with MELAS]. No To Hattatsu, 1991. 23(4): p. 411-6. 
52. Yorifuji, T., et al., Nephropathy and growth hormone deficiency in a patient with mitochondrial tRNA(Leu(UUR)) mutation. J Med Genet, 1996. 33(7): p. 621-2.

53. Balestri, P. and S. Grosso, Endocrine disorders in two sisters affected by MELAS syndrome. J Child Neurol, 2000. 15(11): p. 755-8.

54. Rocha, V., et al., Growth hormone deficiency in a patient with mitochondrial disease. J Pediatr Endocrinol Metab, 2015.

55. Berio, A. and A. Piazzi, Multiple endocrinopathies (growth hormone deficiency, autoimmune hypothyroidism and diabetes mellitus) in Kearns-Sayre syndrome. Pediatr Med Chir, 2013. 35(3): p. 137-40.

56. Obara-Moszynska, M., et al., A novel mitochondrial DNA deletion in a patient with Kearns-Sayre syndrome: a late-onset of the fatal cardiac conduction deficit and cardiomyopathy accompanying long-term rGH treatment. BMC Pediatr, 2013. 13: p. 27.

57. Cassandrini, D., et al., Mitochondrial DNA deletion in a child with mitochondrial encephalomyopathy, growth hormone deficiency, and hypoparathyroidism. J Child Neurol, 2006. 21(11): p. 983-5.

58. Gucuyener, K., et al., Mitochondrial deletion in a boy with growth hormone deficiency mimicking cerebral palsy. J Inherit Metab Dis, 1998. 21(2): p. 173-4.

59. Burns, E.C., et al., Growth hormone deficiency in mitochondrial cytopathy. Acta Paediatr Scand, 1982. 71(4): p. 693-7.

60. Romano, S., et al., Variable outcome of growth hormone administration in respiratory chain deficiency. Mol Genet Metab, 2008. 93(2): p. 195-9.

61. Schwartzentruber, J., et al., Mutation in the nuclear-encoded mitochondrial isoleucyl-tRNA synthetase IARS2 in patients with cataracts, growth hormone deficiency with short stature, partial sensorineural deafness, and peripheral neuropathy or with Leigh syndrome. Hum Mutat, 2014. 35(11): p. 1285-9.

62. Haack, T.B., et al., Phenotypic spectrum of eleven patients and five novel MTFMT mutations identified by exome sequencing and candidate gene screening. Mol Genet Metab, 2014. 111(3): p. 342-52.

63. Imagawa, E., et al., Homozygous p.V116* mutation in C12orf65 results in Leigh syndrome. J Neurol Neurosurg Psychiatry, 2016. 87(2): p. 212-6.

64. Barberi, S., et al., Long-term growth hormone therapy in mitochondrial cytopathy. Horm Res, 2004. 62(2): p. 103-6.

65. Berio, A. and A. Piazzi, [Kearns-Sayre syndrome with GH deficiency]. Pediatr Med Chir, 2000. 22(1): p. 43-6.

66. Yau, E.K., et al., A novel mitochondrial DNA deletion in a Chinese girl with Kearns-Sayre syndrome. Hong Kong Med J, 2009. 15(5): p. 374-7.

67. Chen, C.M. and C.C. Huang, Gonadal dysfunction in mitochondrial encephalomyopathies. Eur Neurol, 1995. 35(5): p. 281-6.

68. Chen, C.M., et al., Hypothalamic amenorrhea in a case of mitochondrial encephalomyopathy. J Formos Med Assoc, 1992. 91(12): p. 1195-9.

69. Carod-Artal, F.J., et al., Cognitive dysfunction and hypogonadotrophic hypogonadism in a Brazilian patient with mitochondrial neurogastrointestinal encephalomyopathy and a novel ECGF1 mutation. Eur J Neurol, 2007. 14(5): p. 581-5.

70. Ohkoshi, N., et al., Dysfunction of the hypothalamic-pituitary system in mitochondrial encephalomyopathies. J Med, 1998. 29(1-2): p. 13-29.

71. Lonnqvist, T., et al., Recessive twinkle mutations cause severe epileptic encephalopathy. Brain, 2009. 132(Pt 6): p. 1553-62. 
72. Luoma, P., et al., Parkinsonism, premature menopause, and mitochondrial DNA polymerase gamma mutations: clinical and molecular genetic study. Lancet, 2004. 364(9437): p. 875-82.

73. Pagnamenta, A.T., et al., Dominant inheritance of premature ovarian failure associated with mutant mitochondrial DNA polymerase gamma. Hum Reprod, 2006. 21(10): p. 2467-73.

74. Blok, M.J., et al., The unfolding clinical spectrum of POLG mutations. J Med Genet, 2009. 46(11): p. 776-85.

75. Kalkan, I.H., et al., A novel finding in MNGIE (mitochondrial neurogastrointestinal encephalomyopathy): hypergonadotropic hypogonadism. Hormones (Athens), 2012. 11(3): p. 377-9.

76. Gironi, M., et al., Late-onset cerebellar ataxia with hypogonadism and muscle coenzyme Q10 deficiency. Neurology, 2004. 62(5): p. 818-20.

77. Menezes, M.J., et al., Mutation in mitochondrial ribosomal protein S7 (MRPS7) causes congenital sensorineural deafness, progressive hepatic and renal failure and lactic acidemia. Hum Mol Genet, 2015. 24(8): p. 2297-307.

78. Dallabona, C., et al., Novel (ovario) leukodystrophy related to AARS2 mutations. Neurology, 2014. 82(23): p. 2063-71.

79. Tong, Z.B., et al., Five mutations of mitochondrial DNA polymerase-gamma (POLG) are not a prevalent etiology for spontaneous 46,XX primary ovarian insufficiency. Fertil Steril, 2010. 94(7): p. 2932-4.

80. Suganuma, N., et al., Human ovarian aging and mitochondrial DNA deletion. Horm Res, 1993. 39 Suppl 1: p. 16-21.

81. May-Panloup, P., et al., Mitochondrial DNA in the oocyte and the developing embryo. Curr Top Dev Biol, 2007. 77: p. 51-83.

82. Bentov, Y. and R.F. Casper, The aging oocyte--can mitochondrial function be improved? Fertil Steril, 2013. 99(1): p. 18-22.

83. Zhen, X., et al., Increased Incidence of Mitochondrial Cytochrome C Oxidase 1 Gene Mutations in Patients with Primary Ovarian Insufficiency. PLoS One, 2015. 10(7): p. e0132610.

84. Duncan, A.J., et al., POLG mutations and age at menopause. Hum Reprod, 2012. 27(7): p. 22434.

85. Pierce, S.B., et al., Mutations in mitochondrial histidyl tRNA synthetase HARS2 cause ovarian dysgenesis and sensorineural hearing loss of Perrault syndrome. Proc Natl Acad Sci U S A, 2011. 108(16): p. 6543-8.

86. Morino, H., et al., Mutations in Twinkle primase-helicase cause Perrault syndrome with neurologic features. Neurology, 2014. 83(22): p. 2054-61.

87. Newman, W.G., T.B. Friedman, and G.S. Conway, Perrault Syndrome, in GeneReviews(R), R.A. Pagon, et al., Editors. 1993: Seattle (WA).

88. Pierce, S.B., et al., Mutations in LARS2, encoding mitochondrial leucyl-tRNA synthetase, lead to premature ovarian failure and hearing loss in Perrault syndrome. Am J Hum Genet, 2013. 92(4): p. 614-20.

89. Jenkinson, E.M., et al., Perrault syndrome is caused by recessive mutations in CLPP, encoding a mitochondrial ATP-dependent chambered protease. Am J Hum Genet, 2013. 92(4): p. 605-13.

90. Ahmed, S., et al., Exome analysis identified a novel missense mutation in the CLPP gene in a consanguineous Saudi family expanding the clinical spectrum of Perrault Syndrome type-3. J Neurol Sci, 2015. 353(1-2): p. 149-54.

91. Aknin-Seifer, I.E., et al., Is the CAG repeat of mitochondrial DNA polymerase gamma (POLG) associated with male infertility? A multi-centre French study. Hum Reprod, 2005. 20(3): p. 73640. 
92. Poongothai, J., Mitochondrial DNA polymerase gamma gene polymorphism is not associated with male infertility. J Assist Reprod Genet, 2013. 30(9): p. 1109-14.

93. Brusco, A., et al., The polymorphic polyglutamine repeat in the mitochondrial DNA polymerase gamma gene is not associated with oligozoospermia. J Endocrinol Invest, 2006. 29(1): p. 1-4.

94. Calderwood, L., et al., Adrenal Insufficiency in Mitochondrial Disease: A Rare Case of GFERRelated Mitochondrial Encephalomyopathy and Review of the Literature. J Child Neurol, 2015.

95. Artuch, R., et al., Multiple endocrine involvement in two pediatric patients with Kearns-Sayre syndrome. Horm Res, 1998. 50(2): p. 99-104.

96. Boles, R.G., et al., Mitochondrial DNA deletion with Kearns Sayre syndrome in a child with Addison disease. Eur J Pediatr, 1998. 157(8): p. 643-7.

97. Tzoufi, M., et al., A rare case report of simultaneous presentation of myopathy, Addison's disease, primary hypoparathyroidism, and Fanconi syndrome in a child diagnosed with KearnsSayre syndrome. Eur J Pediatr, 2013. 172(4): p. 557-61.

98. Duran, G.P., et al., Large mitochondrial DNA deletion in an infant with addison disease. JIMD Rep, 2012. 3: p. 5-9.

99. Ribes, A., et al., Pearson syndrome: altered tricarboxylic acid and urea-cycle metabolites, adrenal insufficiency and corneal opacities. J Inherit Metab Dis, 1993. 16(3): p. 537-40.

100. Afroze, B., et al., Adrenal insufficiency in a child with MELAS syndrome. Brain Dev, 2014. 36(10): p. 924-7.

101. Guran, T., et al., Rare Causes of Primary Adrenal Insufficiency: Genetic and Clinical Characterization of a Large Nationwide Cohort. J Clin Endocrinol Metab, 2016. 101(1): p. 284-92.

102. Meimaridou, E., et al., Mutations in NNT encoding nicotinamide nucleotide transhydrogenase cause familial glucocorticoid deficiency. Nat Genet, 2012. 44(7): p. 740-2.

103. Prasad, R., et al., Thioredoxin Reductase 2 (TXNRD2) mutation associated with familial glucocorticoid deficiency (FGD). J Clin Endocrinol Metab, 2014. 99(8): p. E1556-63.

104. Prasad, R., et al., Oxidative stress and adrenocortical insufficiency. J Endocrinol, 2014. 221(3): p. R63-73.

105. Sugiana, C., et al., Mutation of C20orf7 disrupts complex I assembly and causes lethal neonatal mitochondrial disease. Am J Hum Genet, 2008. 83(4): p. 468-78.

106. Kasiviswanathan, R. and W.C. Copeland, Biochemical analysis of the G517V POLG variant reveals wild-type like activity. Mitochondrion, 2011. 11(6): p. 929-34.

107. Nicolino, M., et al., Identification of a large-scale mitochondrial deoxyribonucleic acid deletion in endocrinopathies and deafness: report of two unrelated cases with diabetes mellitus and adrenal insufficiency, respectively. J Clin Endocrinol Metab, 1997. 82(9): p. 3063-7.

108. Sasaki, H., et al., Myoclonus, cerebellar disorder, neuropathy, mitochondrial myopathy, and ACTH deficiency. Neurology, 1983. 33(10): p. 1288-93.

109. Bordarier, C., et al., Kearns-sayre syndrome. Two clinico-pathological cases. Neuropediatrics, 1990. 21(2): p. 106-9.

110. Horwitz, S.J. and U. Roessmann, Kearns-Sayre syndrome with hypoparathyroidism. Ann Neurol, 1978. 3(6): p. 513-8.

111. Wilichowski, E., et al., Hypoparathyroidism and deafness associated with pleioplasmic large scale rearrangements of the mitochondrial DNA: a clinical and molecular genetic study of four children with Kearns-Sayre syndrome. Pediatr Res, 1997. 41(2): p. 193-200.

112. Ashrafzadeh, F., et al., Hypoparathyroidism as the first manifestation of kearns-sayre syndrome: a case report. Iran J Child Neurol, 2013. 7(4): p. 53-7.

113. Agus, Z.S., Hypomagnesemia. J Am Soc Nephrol, 1999. 10(7): p. 1616-22. 
114. Lee, Y.S., et al., Mitochondrial tubulopathy: the many faces of mitochondrial disorders. Pediatr Nephrol, 2001. 16(9): p. 710-2.

115. Katsanos, K.H., et al., Severe hypomagnesemia and hypoparathyroidism in Kearns-Sayre syndrome. Am J Nephrol, 2001. 21(2): p. 150-3.

116. Tanaka, K., et al., Diabetes mellitus, deafness, muscle weakness and hypocalcemia in a patient with an A3243G mutation of the mitochondrial DNA. Intern Med, 2000. 39(3): p. 249-52.

117. Isotani, H., et al., Hypoparathyroidism and insulin-dependent diabetes mellitus in a patient with Kearns-Sayre syndrome harbouring a mitochondrial DNA deletion. Clin Endocrinol (Oxf), 1996. 45(5): p. 637-41.

118. Toppet, M., et al., Oculocraniosomatic neuromuscular disease with hypoparathyroidism. Am J Dis Child, 1977. 131(4): p. 437-41.

119. Pfeffer, G., et al., Multisystem disorder in late-onset chronic progressive external ophthalmoplegia. Can J Neurol Sci, 2011. 38(1): p. 119-23.

120. Hu, H., et al., Mutations in PTRH2 cause novel infantile-onset multisystem disease with intellectual disability, microcephaly, progressive ataxia, and muscle weakness. Ann Clin Transl Neurol, 2014. 1(12): p. 1024-35. 


\section{Figure Legends}

\section{Figure 1: Oxidative Phosphorylation}

The respiratory chain and oxidative phosphorylation system are embedded in the inner mitochondrial membrane, and represent the major site of ATP production within the cell. Transfer of electrons derived from $\mathrm{NADH}$ and $\mathrm{FADH}_{2}$ is coupled to proton pumping to generate an electrochemical gradient across the inner mitochondrial membrane. This electrochemical gradient is harnessed by ATP synthase to drive the synthesis of ATP from ADP and inorganic phosphate ( $\mathrm{Pi}$ ). Five different protein complexes are involved: NADH-ubiquinone oxidoreductase (Complex I), succinate ubiquinone oxidoreductase (Complex II), ubiquinone cytochrome $c$ oxidoreductase (Complex III), cytochrome $c$ oxidase (Complex IV) and ATP synthase (Complex V), in addition to two mobile electron carriers: coenzyme $Q_{10}(Q)$ and cytochrome $c$ (Cyt c).

Figure 2: $\quad$ Endocrine Dysfunction in Mitochondrial Disease and their Associated Gene Defects

Figure 3: $\quad$ Flowchart for Diagnosis of Endocrine Manifestations of Mitochondrial Disease 


\section{Box 1: Key Points}

- Respiratory chain function and oxidative phosphorylation are affected in primary mitochondrial diseases.

- Mitochondria are present in all cells except mature erythrocytes, and defects in mitochondrial energy metabolism can lead to multi-system organ dysfunction.

- Since all steroid hormones are synthesised within mitochondria, lack of ATP generated from mitochondrial dysfunction can lead to impaired hormone production.

- Endocrine abnormalities are well recognised complications in mitochondrial disorders, observed most frequently in syndromes caused by large-scale mtDNA rearrangements such as Kearns-Sayre syndrome.

- Hormonal insufficiency from endocrine organ failure can occur, including diabetes mellitus, ovarian failure, adrenal insufficiency and hypoparathyroidism.

- Endocrine dysfunction may be the presenting feature of mitochondrial disease, preceding neurological symptomatology.

- Mitochondrial disease should be suspected in a patient presenting with multi-systemic disease and endocrine abnormalities.

Table 1: $\quad$ Examples of Mitochondrial Syndromes

\begin{tabular}{|c|c|c|c|}
\hline $\begin{array}{l}\text { Mitochondrial } \\
\text { syndromes }\end{array}$ & Clinical phenotype & $\begin{array}{l}\text { Associated gene } \\
\text { defects }\end{array}$ & Inheritance \\
\hline Alpers-Huttenlocher & $\begin{array}{l}\text { Infantile onset of } \\
\text { developmental delay or } \\
\text { regression, intractable } \\
\text { epilepsy, +/- liver failure }\end{array}$ & $\begin{array}{l}\text { POLG, FARS2, } \\
\text { NARS2, PARS2 }\end{array}$ & Autosomal recessive \\
\hline *Kearns-Sayre syndrome & $\begin{array}{l}\text { Progressive external } \\
\text { ophthalmoplegia, retinitis } \\
\text { pigmentosa, } \\
\text { cardiomyopathy, heart block }\end{array}$ & mtDNA deletion & Usually sporadic \\
\hline $\begin{array}{l}\text { Leber hereditary optic } \\
\text { neuropathy } \\
\text { (LHON) }\end{array}$ & Optic neuropathy & $\begin{array}{l}\text { mtDNA point } \\
\text { mutations (most } \\
\text { commonly m. } \\
\text { m.11778G }>A \text {, } \\
\text { m.3460G }>\text { A and } \\
\text { m.14484T>C) }\end{array}$ & Maternal \\
\hline Leigh syndrome & $\begin{array}{l}\text { Subacute relapsing } \\
\text { encephalopathy of infantile } \\
\text { onset }\end{array}$ & $>75$ genes & $\begin{array}{l}\text { Maternal; Autosomal } \\
\text { recessive; X-linked }\end{array}$ \\
\hline $\begin{array}{l}\text { Mitochondrial DNA } \\
\text { depletion syndromes }\end{array}$ & $\begin{array}{l}\text { Hepatocerebral, myopathic } \\
\text { and encephalopathic } \\
\text { variants }\end{array}$ & $\begin{array}{l}\text { POLG, DGUOK, } \\
\text { MPV17, C10orf2, } \\
\text { TK2, SUCLA2, } \\
\text { SUCLG1, RRM2B, } \\
\text { FBXL4, MGME1 }\end{array}$ & Autosomal recessive \\
\hline *Mitochondrial & Stroke-like episodes before & MT-TL1 & Maternal \\
\hline
\end{tabular}




\begin{tabular}{|c|c|c|c|}
\hline $\begin{array}{l}\text { encephalomyopathy with } \\
\text { lactic acidosis and stroke- } \\
\text { like episodes } \\
\text { (MELAS) }\end{array}$ & $\begin{array}{l}40 \text { years, seizures, migraine, } \\
\text { cognitive decline, lactic } \\
\text { acidosis, childhood onset } \\
\text { muscle weakness }\end{array}$ & $\begin{array}{l}\text { ( } \mathrm{m} .32423 \mathrm{~A}>\mathrm{G} \text { in } 80 \% \\
\text { cases) and other } \\
\text { mtDNA point } \\
\text { mutations }\end{array}$ & \\
\hline $\begin{array}{l}\text { Myoclonic epilepsy } \\
\text { myopathy sensory ataxia } \\
\text { (MEMSA) }\end{array}$ & $\begin{array}{l}\text { Myopathy, seizures, } \\
\text { cerebellar ataxia }\end{array}$ & POLG & Autosomal recessive \\
\hline $\begin{array}{l}\text { Myoclonic epilepsy with } \\
\text { ragged-red fibers } \\
\text { (MERRF) }\end{array}$ & $\begin{array}{l}\text { Myoclonus, seizures, } \\
\text { cerebellar ataxia, myopathy }\end{array}$ & $\begin{array}{l}M T-T K(\mathrm{~m} .8344 \mathrm{~A}>\mathrm{G}) \\
\text { and other mtDNA } \\
\text { point mutations, } \\
\text { POLG }\end{array}$ & $\begin{array}{l}\text { Maternal; Autosomal } \\
\text { recessive }\end{array}$ \\
\hline $\begin{array}{l}\text { *Maternally inherited } \\
\text { diabetes and deafness } \\
\text { (MIDD) }\end{array}$ & Diabetes and deafness & MT-TL1 (m.3243A>G) & Maternal \\
\hline $\begin{array}{l}\text { Mitochondrial } \\
\text { neurogastrointestinal } \\
\text { encephalopathy } \\
\text { (MNGIE) }\end{array}$ & $\begin{array}{l}\text { Progressive gastrointestinal } \\
\text { dysmotility, } \\
\text { ophthalmoplegia, } \\
\text { leukoencephalopathy, } \\
\text { peripheral neuropathy }\end{array}$ & $\begin{array}{l}\text { TYMP } \\
\text { (similar symptoms } \\
\text { may occur with } \\
\text { POLG, RRM2B, MT- } \\
T L 1, M T-T V \\
\text { mutations) } \\
\end{array}$ & $\begin{array}{l}\text { Autosomal recessive; } \\
\text { Maternal }\end{array}$ \\
\hline $\begin{array}{l}\text { Neurogenic weakness } \\
\text { with ataxia and retinitis } \\
\text { pigmentosa } \\
\text { (NARP) }\end{array}$ & $\begin{array}{l}\text { Late childhood or adult } \\
\text { onset peripheral } \\
\text { neuropathy, ataxia, } \\
\text { retinopathy }\end{array}$ & $\begin{array}{l}\text { MT-ATP6 (most } \\
\text { commonly } \\
\mathrm{m} .8993 \mathrm{~T}>\mathrm{G} / \mathrm{C} \text { ) }\end{array}$ & Maternal \\
\hline *Pearson syndrome & $\begin{array}{l}\text { Sideroblastic anaemia, } \\
\text { pancytopenia, exocrine } \\
\text { pancreatic dysfunction }\end{array}$ & mtDNA deletion & Usually sporadic \\
\hline *Perrault syndrome & $\begin{array}{l}\text { Premature ovarian } \\
\text { insufficiency, sensorineural } \\
\text { hearing loss }\end{array}$ & $\begin{array}{l}\text { C10orf2, CLPP, } \\
\text { HARS2, LARS2 }\end{array}$ & Autosomal recessive \\
\hline $\begin{array}{l}\text { Progressive external } \\
\text { ophthalmoplegia (PEO) }\end{array}$ & $\begin{array}{l}\text { Progressive external } \\
\text { ophthalmoplegia +/- skeletal } \\
\text { myopathy }\end{array}$ & $\begin{array}{l}\text { mtDNA deletions; } \\
\text { mtDNA mutations; } \\
\text { POLG, C10orf2, } \\
\text { RRM2B, SLC25A4 }\end{array}$ & $\begin{array}{l}\text { Sporadic; maternal; } \\
\text { autosomal dominant }\end{array}$ \\
\hline $\begin{array}{l}\text { Sensory ataxia, } \\
\text { neuropathy, dysarthria, } \\
\text { ophthalmoparesis } \\
\text { (SANDO) }\end{array}$ & $\begin{array}{l}\text { Ataxia, peripheral } \\
\text { neuropathy, eye movement } \\
\text { disorders, epilepsy, cognitive } \\
\text { impairment, psychiatric } \\
\text { symptoms, involuntary } \\
\text { movements (part of ataxia } \\
\text { neuropathy spectrum) }\end{array}$ & POLG, C10orf2, OPA1 & Autosomal recessive \\
\hline
\end{tabular}

*Endocrine dysfunction commonly described

Table 2: Gene defects associated with endocrine manifestations in mitochondrial disease 


\begin{tabular}{|c|c|c|c|}
\hline $\begin{array}{l}\text { Endocrine } \\
\text { manifestation }\end{array}$ & Gene defect(s) & $\begin{array}{l}\text { Inheritance } \\
\text { mode }\end{array}$ & Molecular mechanism \\
\hline Diabetes mellitus & $\begin{array}{l}\text { MT-TL1, MT-TK, MT-TS2, MT-TE } \\
\text { Large-scale mtDNA deletion } \\
\text { POLG, RRM2B, OPA1, MPV17 }\end{array}$ & $\begin{array}{l}\text { Maternal } \\
\text { Sporadic }\end{array}$ & $\begin{array}{l}\text { Impaired translation } \\
\text { Impaired translation } \\
\text { Impaired mtDNA maintenance }\end{array}$ \\
\hline $\begin{array}{l}\text { Short stature \& } \\
\text { Growth hormone } \\
\text { insufficiency }\end{array}$ & $\begin{array}{l}\text { MT-TL1, MT-TK } \\
\text { Large-scale mtDNA deletion } \\
\text { IARS2, MTFMT, C12orf65 } \\
\text { NDUFA4, SURF1, COX10, LRPPRC } \\
\text { ECHS1 }\end{array}$ & $\begin{array}{l}\text { Maternal } \\
\text { Sporadic } \\
\text { AR } \\
\text { AR } \\
\text { AR }\end{array}$ & $\begin{array}{l}\text { Impaired translation } \\
\text { Impaired translation } \\
\text { Impaired translation } \\
\text { Impaired complex IV } \\
\text { Oxidative stress }\end{array}$ \\
\hline $\begin{array}{l}\text { Hypergonadotrophic } \\
\text { hypogonadism }\end{array}$ & $\begin{array}{l}\text { STAR, CYP11A1, HSD3B2 } \\
\text { C10orf2, POLG, TYMP } \\
\text { LRPPRC, MRPS7, AARS2 }\end{array}$ & $\begin{array}{l}\text { AR } \\
\text { AR } \\
\text { AR } \\
\end{array}$ & $\begin{array}{l}\text { Impaired mitochondrial } \\
\text { steroidogenesis } \\
\text { Impaired mtDNA maintenance } \\
\text { Impaired translation }\end{array}$ \\
\hline $\begin{array}{l}\text { Hypogonadotrophic } \\
\text { hypogonadism }\end{array}$ & $\begin{array}{l}\text { MT-TL1, MT-TK } \\
\text { Large-scale mtDNA deletion } \\
\text { TYMP }\end{array}$ & $\begin{array}{l}\text { Maternal } \\
\text { Sporadic } \\
\text { AR }\end{array}$ & $\begin{array}{l}\text { Impaired translation } \\
\text { Impaired translation } \\
\text { Impaired mtDNA maintenance }\end{array}$ \\
\hline $\begin{array}{l}\text { Primary ovarian } \\
\text { insufficiency or } \\
\text { premature } \\
\text { menopause }\end{array}$ & $\begin{array}{l}\text { POLG } \\
\text { C12orf65, LRPPRC } \\
\text { COX10 } \\
\text { CLPB }\end{array}$ & $\begin{array}{l}\text { AD or } A R \\
A R \\
A R \\
A R\end{array}$ & $\begin{array}{l}\text { Impaired mtDNA maintenance } \\
\text { Impaired translation } \\
\text { Impaired complex IV assembly } \\
\text { Impaired mitochondrial quality } \\
\text { control }\end{array}$ \\
\hline Perrault syndrome & $\begin{array}{l}\text { C10orf2 } \\
\text { HARS2, LARS2 } \\
\text { CLPP }\end{array}$ & $\begin{array}{l}\text { AR } \\
\text { AR } \\
\text { AR }\end{array}$ & $\begin{array}{l}\text { Impaired mtDNA maintenance } \\
\text { Impaired translation } \\
\text { Impaired mitochondrial quality } \\
\text { control }\end{array}$ \\
\hline Adrenal insufficiency & $\begin{array}{l}\text { STAR, CYP11A1, HSD3B2 } \\
\text { Large-scale mtDNA deletion } \\
\text { MT-TK } \\
\text { MRPS7, QRSL1 } \\
\text { NDUFAF5 } \\
\text { GFER } \\
\text { NNT, TXNRD2 }\end{array}$ & $\begin{array}{l}\text { AR } \\
\text { Sporadic } \\
\text { Maternal } \\
\text { AR } \\
\text { AR } \\
\text { AR } \\
\text { AR }\end{array}$ & $\begin{array}{l}\text { Impaired mitochondrial } \\
\text { steroidogenesis } \\
\text { Impaired translation } \\
\text { Impaired translation } \\
\text { Impaired translation } \\
\text { Impaired complex I assembly } \\
\text { Impaired mitochondrial import } \\
\text { Oxidative stress }\end{array}$ \\
\hline Hypoparathyroidism & $\begin{array}{l}\text { Large-scale mtDNA deletion } \\
M T-T L 1\end{array}$ & $\begin{array}{l}\text { Sporadic } \\
\text { Maternal }\end{array}$ & $\begin{array}{l}\text { Impaired translation } \\
\text { Impaired translation }\end{array}$ \\
\hline Hypothyroidism & $\begin{array}{l}\text { MT-TL1 } \\
\text { PTRH2 }\end{array}$ & $\begin{array}{l}\text { Maternal } \\
\text { AR }\end{array}$ & $\begin{array}{l}\text { Impaired translation } \\
\text { Impaired translation }\end{array}$ \\
\hline
\end{tabular}

Key: $A D=$ autosomal dominant; $A R=$ autosomal recessive; Perrault syndrome $=$ ovarian dysgenesis and sensorineural hearing loss 


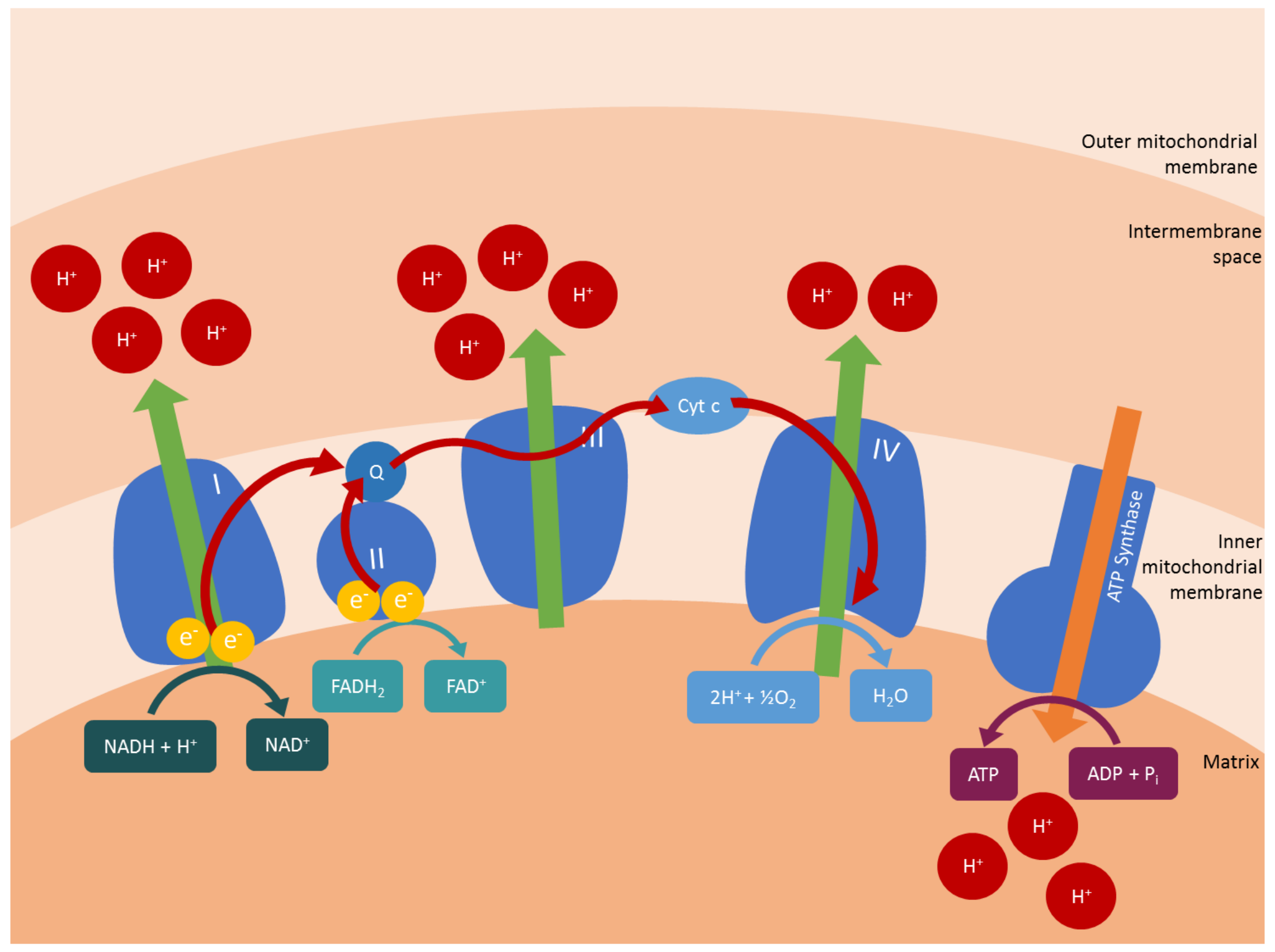


Hypothalamus and pituitary gland -Growth hormone deficiency -Hypogonadotrophic hypogonadism -Secondary adrenal insufficiency -Central hypothyroidism

Affected genes:

MT-TL1, MT-TK, large-scale mtDNA deletion, IARS2, MTFMT, C12orf65, NDUFA4, SURF1, COX10, LRPPRC , ECHS1

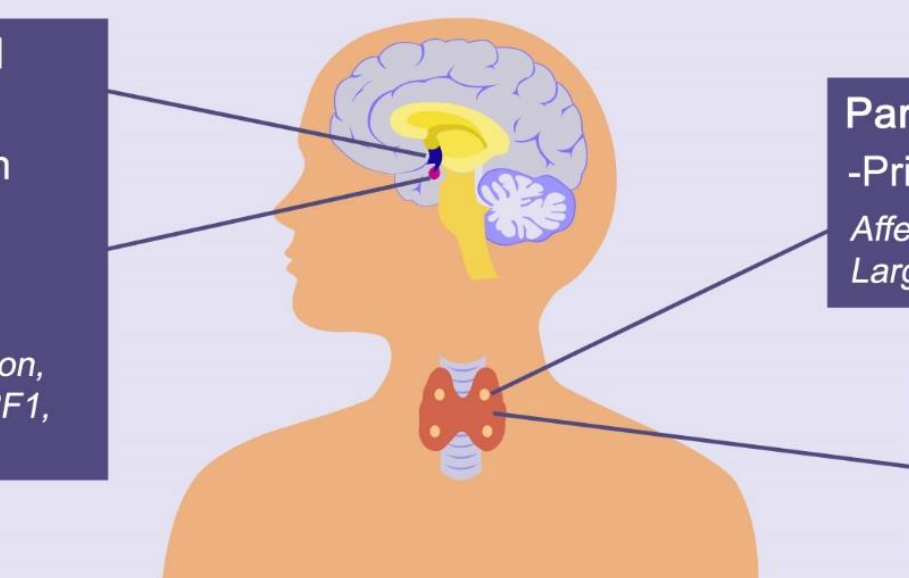

Parathyroid glands

-Primary hypoparathyroidism

Affected genes:

Large-scale mtDNA deletion, MT-TL1

Adrenal glands
-Primary adrenal insufficiency
Affected genes:
STAR, CYP11A1, HSD3B2, MT-TK, large-
scale mtDNA deletion, MRPS7, QRSL1,
NDUFAF5, GFER, NNT, TXNRD2

Testes

-Hypergonadotrophic hypergonadism

Affected genes:

STAR, CYP11A1, HSD3B2,

POLG, C10orf2, TYMP,

LRPPRC
Thyroid gland

-Primary hypothyroidism

Affected genes: MT-TL1, PTRH2

Pancreas

-Diabetes mellitus

-Exocrine pancreatic

insufficiency

Affected genes:

MT-TL1, MT-TK, MT-TS2, MT-TE, large-scale mtDNA deletion, POLG, RRM2B, OPA1, MPV17

Ovaries

-Primary ovarian insufficiency -Perrault syndrome

Affected genes:

POLG, C12orf65, LRPPRC, CLPP COX10, CLPB, AARS2, C10orf2, HARS2, LARS2, 


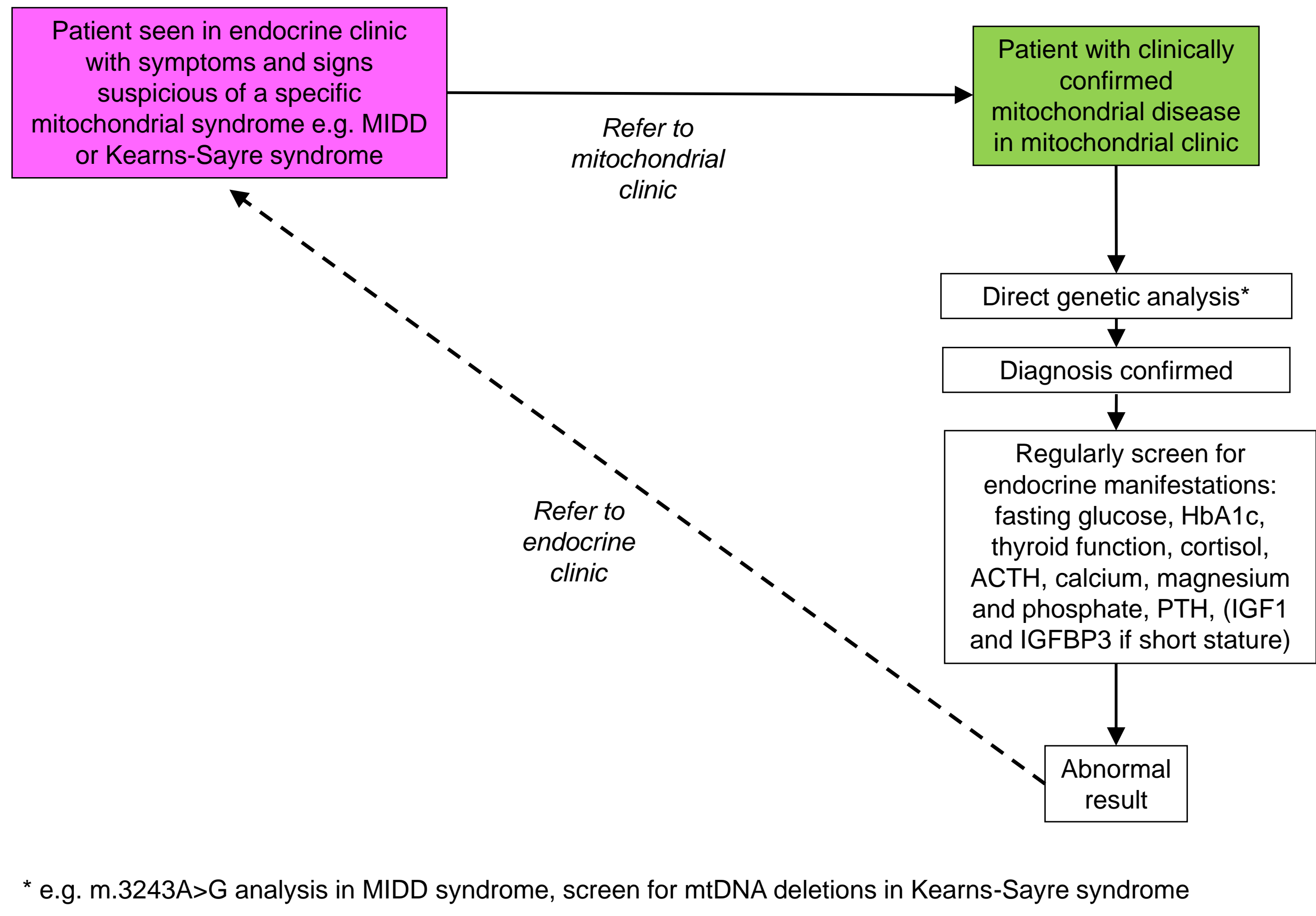

